\title{
On the blue colour of ultramarine
}

\section{Elsner}

To cite this article: M. Elsner (1842) On the blue colour of ultramarine, Philosophical Magazine Series 3, 21:136, 156-157, DOI: 10.1080/14786444208621504

To link to this article: http://dx.doi.org/10.1080/14786444208621504

册 Published online: 01 Jun 2009.

Submit your article to this journal 준

LII Article views: 3

Q View related articles $₫$ 
it, accompanied by a noise which made them think that one of our shafts had crushed in, or runned together; but on examining with Capt. Crose, who was in the mine, we could find nothing at all amiss, or any cause for the shock."

This appears to be the most westerly part at which the tremor was felt, and although the noise was heard away to the south, towards the Lizard, it is clear it was much diminished in force.

On referring to a geological map of the county, it will be found that the greatest effects were produced near the edge of the granite mass, which extends from the north-east to the south-west, from Carn Marth to the south of Penryn. Although it was felt at Falmouth, Helstone, and other places which are on the clay-slate, yet all my inquiries go to show that it diminished rapidly in force, as the distance from the granite increased*.

A gentleman of Helstone says, "I felt it very sensibly, and my house shook, but I experienced an effect on the sight which I always find attends electricity;" from which he appears inclined to deem the disturbance as atmospheric. Had that been the case, it would not have been felt in the mines; but it is not improbable that a manifestation of electricity may have attended this disturbance of the earth.

ON THE BLUE COLOUR OF ULTRAMARINE. BY M. ELSNER.

According to all analyses hitherto published, ultramarine is composed principally of soda, alumina, silica and sulphur, as shown by the following statements :-

Lapis Lazuli.

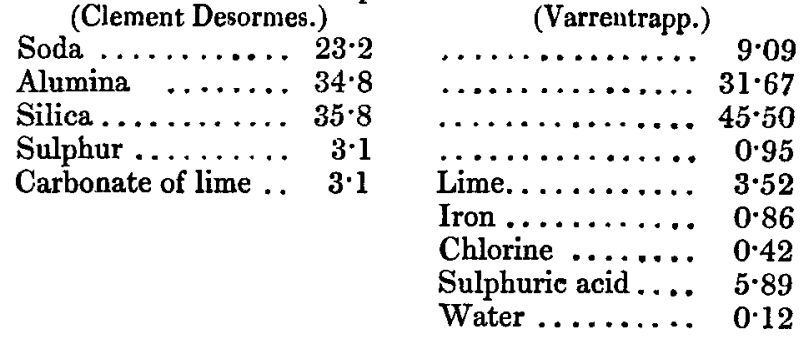

Artificial Ultramarine of Paris.

(C. G. Gmelin.)

Soda (mixed with potash) $12 \cdot 063$

Lime ....................... 1.546

Alumina ......... 22.000

Silica ........... 47:306

Sulphuric acid ..... 4.679

Sulphur ......... 0.188

Resinous substance, sul- $\} 12 \cdot 218$

Artificial Ultramarine manufacture

of Meissen.

(Varrentrapp.)

Soda........... 21.47

Potash ......... 1.75

Lime . . . . . . . . . 0.02

Alumina ........ 23.30

Silica ......... 45.00

Sulphuric acid ..... $\quad 3.83$

Sulphur......... I.683

Iron .......... 1.063

* Mr. Hunt here adds some remarks on the condition of the atmosphere, and the heights of the barometer and thermometer at the period of the earthquake. 
It appears that the analyses of Varrentrapp only, give iron as present in these substances, and which is essential to the production of the blue colour of ultramarine : lapis lazuli is well known to contain iron pyrites.

M. Elsner has analysed the blue and green varieties of ultramarine from Nuremberg, and he found them to be composed as follows:-

Blue Ultramarine.

Silica ......... $40 \cdot 0$

Alumina ....... 29.5

Soda.......... $23 \cdot 0$

Sulphuric acid .... $3 \cdot 4$

Sulphur ...... $4 \cdot 0$

Peroxide of iron .. $\frac{1 \cdot 0}{100 \cdot 9}$
Green Ultramarine.

....... $39 \cdot 9$

....... $30 \cdot 0$

$\ldots \ldots \ldots 25 \cdot 5$

(...... $\cdot 4$

....... $4 \cdot 6$

… $\quad \cdot 9$

$101 \cdot 3$

These contained traces of chlorine, potash, lime and magnesia. These analyses show that there is much more sulphur present than is required for the production of a simple sulphuret of iron; this excess of sulphur can be combined only with the sodium; and it results also from the analysis, as is also shown by synthetical researches, that sulphuret of sodium is not less necessary than sulphuret of iron to the production of ultramarine.-Journal de Pharm. et de Chim., Avril 1842 .

PREPARATION OF OXICHLORIC ACID. BY M. AD.NATIVELLE.

Oxichloric acid, which is so useful as a reagent, $M$. Nativelle remarks, is seldom to be found in laboratories; and he supposes this to be owing to the small quantity of it which is obtained by employing the proportion of sulphuric acid usually recommended in chemical works: he gives the following process as separating the whole of the acid from the oxichlorate of potash :-

Put into a glass retort 500 parts of oxichlorate of potash reduced to powder, deprived as much as possible of chlorate; add 1000 parts of sulphuric acid of specific gravity $1 \cdot 845$, and 100 parts of distilled water; this small quantity of water is not indispensable, for it will be shown that, by omitting it, oxichloric acid is cbtained in the crystalline state. An adopter with a long tube is to be passed into a tabulated retort, surrounded with cold water; the apparatus must not be luted with any organic substance, for the oxichloric acid gas coming into contact with it while hot decomposes it and produces slight detonations; when proper vessels are employed lute need not be employed, but, when required, filaments of amianthus answer the purpose. The oxichlorate is to be carefully heated; it readily dissolves, and the fire must be regulated so as to prevent the oxichloric acid from carrying over with it too much sulphuric acid. The best method of regulating the operation is to keep below the boiling point; but little sulphuric acid goes over, for oxichloric acid volatilizes at $284^{\circ}$, which is much lower than the temperature at which sulphuric acid distils. The operation is complete when the residue in the retort is transparent and colourless, or when the product drops very slowly and the temperature of the retort is nearly sufficient to volatilize sulphuric acid; the weight of the product de- 